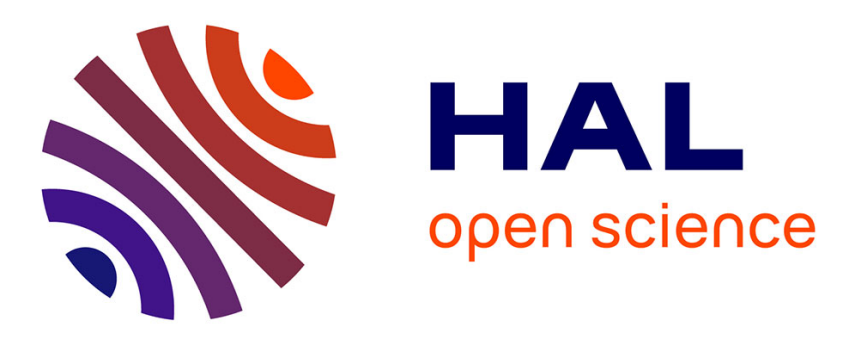

\title{
Moderate clinical improvement with maintenance ECT in a 17-year-old boy with intractable catatonic schizophrenia
}

Angèle Consoli, Valérie Boulicot, Françoise Cornic, Philippe Fossati, Martine Barbeau, David Cohen

\section{To cite this version:}

Angèle Consoli, Valérie Boulicot, Françoise Cornic, Philippe Fossati, Martine Barbeau, et al.. Moderate clinical improvement with maintenance ECT in a 17 -year-old boy with intractable catatonic schizophrenia. European Child and Adolescent Psychiatry, 2009, 18 (4), pp.250-254. 10.1007/s00787008-0724-6 . hal-00486569

\section{HAL Id: hal-00486569 https://hal.science/hal-00486569}

Submitted on 26 May 2010

HAL is a multi-disciplinary open access archive for the deposit and dissemination of scientific research documents, whether they are published or not. The documents may come from teaching and research institutions in France or abroad, or from public or private research centers.
L'archive ouverte pluridisciplinaire HAL, est destinée au dépôt et à la diffusion de documents scientifiques de niveau recherche, publiés ou non, émanant des établissements d'enseignement et de recherche français ou étrangers, des laboratoires publics ou privés. 


\section{Angèle Consoli Valérie Boulicot Françoise Cornic Philippe Fossati Martine Barbeau David Cohen}

\section{Moderate clinical improvement with maintenance ECT in a 17-year-old boy with intractable catatonic schizophrenia}

Received: 17 April 2008

Accepted: 19 August 2008

Published online: 20 January 2009
A. Consoli, MD $\cdot$ M. Barbeau, $\mathrm{PhD} \cdot \mathrm{D}$. Cohen, MD, PhD $(\bowtie)$ Department of Child and Adolescent Psychiatry

APHP, CNRS, Groupe Hospitalier Pitié-Salpêtrière

Université Pierre et Marie Curie 47-3 Bd de l'Hôpital

75651 Paris Cedex 13, France

E-Mail: david.cohen@psl.aphp.fr

A. Consoli, MD - F. Cornic, MD

D. Cohen, MD, PhD

CNRS UMR 8189 "Psychologie et

Neurosciences Cognitives"

Paris, France

V. Boulicot, MD $\cdot$ F. Cornic, MD

Department of Psychiatry

Hôpital Saint-Antoine

Paris, France
Abstract The use of electroconvulsive therapy (ECT) in adolescents is controversial, and few studies have been conducted to assess its efficacy and safety in this population. We report the case of a 19-year-old boy who received two series of ECT, one at 15 and another at 16 , for intractable catatonic schizophrenia. Since the age of 17 , he has required treatment combining clozapine and maintenance ECT. The course showed a sustained moderate improvement. The treatment

F. Cornic, MD

Department of Psychiatry Hôpital Sainte-Anne

Paris, France

P. Fossati, MD, PhD

Department of Psychiatry Hôpital Pitié-Salpêtrière

Paris, France permitted the patient to regain some autonomy with moderate adverse effects. ECT remains an uncommon treatment in adolescents, and the current case supports the view that it should not be banned in young people.

Key words catatonic schizophrenia - adolescent electro-convulsive therapy maintenance ECT

\section{Introduction}

The use of electro-convulsive therapy (ECT) in adolescents was first reported by Heuyer et al. in 1942. It has become very rare since the appearance of antipsychotic drugs, and its frequency is now estimated to range between 0.5 and 1 adolescent per million every year [15]. Several reports showed that ECT can be a safe and effective treatment for adolescents with is intractable mood disorders, in particular when pa- tients exhibit catatonic or psychotic symptoms. ECT may also be appropriate for some patients with resistant schizophrenia $[7,14,20,21,24-27,29,31$, $38]$. However, some authors $[5,6]$ have raised ethical concerns and alleged unknown secondary cognitive effects to ban ECT use in adolescents. This negative point of view toward the use of ECT in this age group is also codified in the laws of several states in the US [19]. The use of ECT in minors has been prohibited by legislation in California (1974; for minors under age 12), Tennessee (1976; under age 14), Colorado (1977; 
under age 15), and more recently Texas (1993; under age 16). However, both the American Psychiatric Association [3] and the American Academy of Child and Adolescent Psychiatry [22] do not consider age as a contraindication. In France, the use of ECT in teenagers is not prohibited, and guidelines are very similar to those formulated by the APA [1].

Here, we report the case of an adolescent with intractable catatonic schizophrenia for whom maintenance ECT, given since age 17, resulted in moderate symptom improvement.

\section{Case report}

\section{History and psychiatric assessment}

J., a 14-year-old European male patient, was hospitalised in the Department of Child and Adolescent Psychiatry at Pitié-Salpétrière Hospital due to severe behavioural symptoms including school refusal with insidious onset. Family history and patient's history were unremarkable. The diagnosis of catatonic schizophrenia was accepted for this patient; psychotic symptoms included auditory and tactile hallucinations, "echophenomena", and delusions of persecution; catatonic symptoms included automatic compulsive movements secondary to hallucinations, stereotypies, verbigeration, negativism, periodic psychomotor excitement, and refusal to eat. We also observed incontinence and social withdrawal. At admission, the patient was scored on the clinical global impression-severity (CGI-S) and the global assessment of functioning scale (GAF). We also used the modified Bush-Francis Catatonia rating scale [9, 13 ], in which each catatonic symptom was rated on a scale from 0 to 3, leading to a maximum score of 60 . The CGI-S score at entry was 7, the GAF score was 10, and the Catatonia rating scale score was 18. Extensive laboratory evaluations, including LCR examination and diagnostic imaging, were all unremarkable. Adequate trials of lorazepam ( $5 \mathrm{mg} /$ day), amisulpiride $(1,200 \mathrm{mg} /$ day $)$, thioridazine ( $30 \mathrm{mg} /$ day), haloperidol (10 mg/day), olanzapine (20 mg/day), and flupentixol (60 mg/day), alone or in combination, yielded minimal response with significant adverse effects, in particular extra-pyramidal symptoms and sedation. The patient also received pack therapy ${ }^{1}$ (two sessions per week for eight consecutive weeks), an adjuvant treatment used for severe psychotic states in children and adolescents $[11,12]$, also with no improvement.

\footnotetext{
${ }^{1}$ Pack therapy: envelopment in damp sheets for $1 \mathrm{~h}$ sessions with the patient expressing body and corporal feelings and spontaneous fantasies. An example is given in case 2 of Cohen's report [11].
}

\section{ECT parameters}

Because the patient's symptoms persisted with severe impairment and poor autonomy, the use of ECT was considered. This was discussed with both parents extensively. After the patient's and his parents' consent, we started a course of ECT. All other treatments were discontinued. Anaesthesia for ECT was induced using intravenous propofol (60$250 \mathrm{mg}$, mean $173 \mathrm{mg}$ ), and muscle relaxation was achieved with intravenous suxamethonium (50$100 \mathrm{mg}$, mean $63 \mathrm{mg}$ ). ECT was administered using a Thymatron-IV device that produces a brief pulse electric current (pulse width $1.0 \mathrm{~ms}$, pulse duration $3.2 \mathrm{~s}$ ) with a $30-70 \mathrm{~Hz}$ frequency. The electrical stimulus was applied using the standard bilateral electrode position with $10-30 \%$ energy (0.75$0.92 \mathrm{~A}$ ). Consecutive pulses ended when a seizure of at least $30 \mathrm{~s}$ was elicited.

A course of 15 bilateral ECT treatments was first administered. After the seventh session, the symptoms gradually decreased, reaching a GAF score of 41 . The catatonic symptoms paralleled GAF improvement, as evidenced by a decrease in the patient's Catatonia rating scale score from 20 before ECT to 8 after ECT. This allowed the patient to be discharged from the hospital. Treatment with olanzapine, $15 \mathrm{mg} /$ day, was started. The clinical improvement lasted one month, but then the patient's symptoms worsened, requiring a second hospitalisation. The patient first received increasing doses of clozapine up to $450 \mathrm{mg} /$ day with blood monitoring, but showed no improvement and sedation. A second course of 20 ECT sessions was administered after clozapine disruption. Again, a moderate but clear improvement occurred (Fig. 1). The patient refused to continue with maintenance ECT because of subjective memory impairments. Clozapine was re-administered at a dosage of $300 \mathrm{mg} /$ day.

Unfortunately, the patient did not maintain the moderate improvement, and his condition again worsened. After a second opinion from another University Department, he accepted maintenance ECT. $\mathrm{He}$ was 17 years old when the treatment began. He received eight acute ECT sessions, then continued with maintenance ECT (once per week, then every 2 weeks, then every 4 weeks). Again, a moderate improvement occurred, despite his condition remaining severe. The patient was able to participate in activities and regain autonomy. Figure 1 summarises the course of the symptom severity relative to ECT sessions. Residual symptoms included anxiety, mild catatonic signs (automatic compulsive movements and negativism) and social withdrawal. He never returned to school or home and needed residential care for the following 3 years. He was able to 


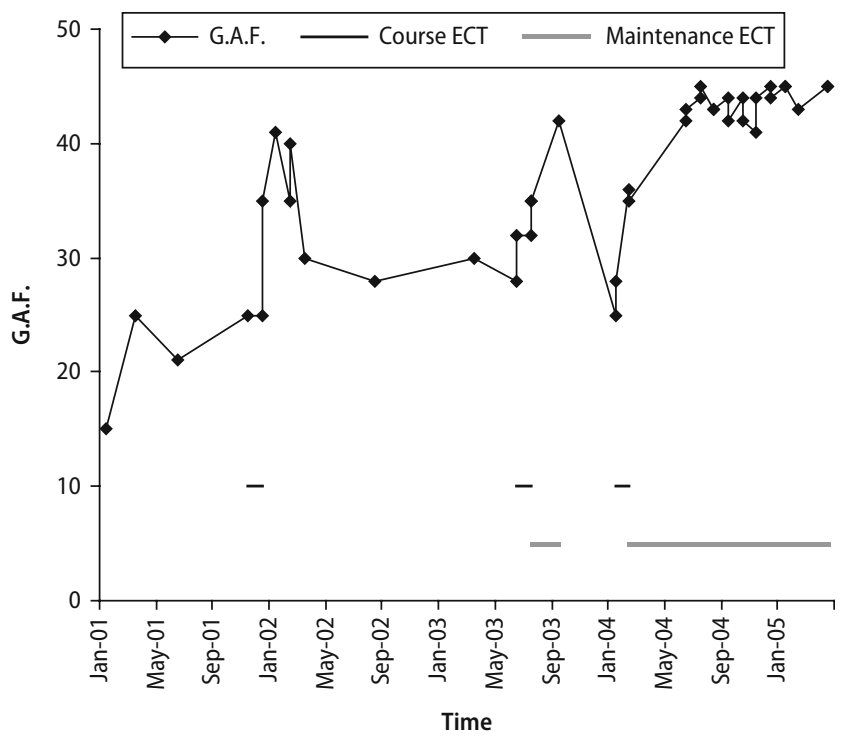

Fig. 1 Global assessment functioning score course in a 19-year-old adolescent treated with maintenance ECT since 17 years of age for intractable catatonic schizophrenia

visit his family on weekends and to participate in regular sessions of milieu therapy, including theatre.

\section{Monitoring of adverse effects}

Adverse effects were monitored as recommended [22]. In particular, cognitive assessments were given before treatment, after acute ECT treatment, at 6 and 18 months during maintenance ECT. Table 1 summarises the data. The quality of the assessment was limited by the patient's compliance with the testing situation and negativism. Given these limitations, the adverse effects, particularly memory impairment, remained reasonable for our patient at 6 months, as evidenced by global cognition and memory scores. At 18 months, the available data are limited to the minimental state evaluation, the information sub-score of the Weschler adult intelligence scale and the story sub-score of the Wechsler memory scale, because the patient refused to repeat the testing.

Assessment of subjective memory impairment was performed using the Squire's subjective memory questionnaire (SSMQ), in which a score very close to 0 indicates that the patient judges his current memory to be neither worse nor better than before the ECT. After the first course of ECT, the ECT sub-score, the Depression sub-score and the total score were -32 , -8 , and -40 , respectively, indicating marked subjective memory impairment as a consequence of ECT [30]. Although the patient refused to complete the SSMQ again during maintenance ECT, he complained of memory impairments due to ECT. Other secondary effects included mild headaches following some ECT sessions.

\section{Discussion}

To our knowledge, we report the first recent case of maintenance ECT in a young person with catatonic schizophrenia. Two recent papers reported the use of "maintenance" ECT in catatonia comorbid with autism $[4,37]$. However, in these cases the maintenance
Table 1 Cognitive assessment before, after and during maintenance ECT

\begin{tabular}{|c|c|c|c|c|}
\hline & \multicolumn{2}{|l|}{ Acute ECT } & \multicolumn{2}{|c|}{ Maintenance ECT } \\
\hline & Baseline & After ECT & 6 months & 18 months \\
\hline Cumulative number of ECT & 0 & 20 & 32 & 61 \\
\hline \multicolumn{5}{|l|}{ Global cognition } \\
\hline MMS & 25 & 24 & 26 & 27 \\
\hline Information $^{\mathrm{a}}$ & $8 / 10$ & $8 / 10$ & $8 / 10$ & $6 / 10$ \\
\hline Block design ${ }^{a}$ & $9 / 10$ & $7 / 10$ & $8 / 10$ & Refusal \\
\hline \multicolumn{5}{|l|}{ Memory ${ }^{b}$} \\
\hline Story & 8 & 8 & 6 & 3 \\
\hline Pair of words & 6 & 4 & 5 & Refusal \\
\hline Words list & 7 & 6 & 6 & Refusal \\
\hline Number remind & 10 & 7 & 8 & Refusal \\
\hline \multicolumn{5}{|l|}{ Rey figure } \\
\hline Copy organisation & Type 1 & Type 1 & Type 1 & Refusal \\
\hline Copy accuracy & 34 (70 cent) & 30 (50 cent) & 34 (60 cent) & Refusal \\
\hline Delayed organisation & Type 1 & Type 1 & Refusal & Refusal \\
\hline Delayed accuracy & 24 (60 cent) & 18 (60 cent) & Refusal & Refusal \\
\hline SSMQ & NA & -40 & Refusal & Refusal \\
\hline
\end{tabular}

MMS mini-mental state, NA not appropriate, SSMQ Squire's subjective memory questionnaire ${ }^{\text {a }}$ Subscore of the Wechsler intelligence scale for children-III-R for time 1 and 2, Wechsler adult intelligence scale for time 3 and 4

${ }^{\mathrm{b}}$ Children memory scale for time 1 and 2, Wechsler memory scale III for time 3 and 4 
phase was up to 6 months in Wachtel et al.'s report and 27 weeks in Bailine et al.'s report, corresponding to a consolidation phase with gradual tapering rather than the typically longer time course of maintenance ECT (in our case, 2 years) $[19,20]$. In sum, the current case illustrates that ECT is moderately effective in treating symptoms of catatonic schizophrenia. The course of symptom severity shows that: (a) ECT moderately improved the patient's symptom severity on two distinct occasions; (b) antipsychotic medications, including olanzapine and clozapine, did not maintain clinical improvement after ECT; and (c) on the contrary, maintenance ECT with increasing time between sessions allowed the moderate improvement to stabilize (see Fig. 1).

The number of studies of ECT during adolescence is low, and only three controlled studies exist $[7,15$, 25 ]. Even though many controversies persist over the use of ECT in youth, interest in the procedure is growing [18]. Careful utilization is recommended, but its efficacy in the treatment of severe and resistant mood disorders and catatonic syndromes is observable [13]. A literature review from the first use of ECT in children and adolescents in 1942 and 1996 estimated that a total of 396 patients under 18 years old were treated with ECT, but most of the reviewed studies only reported unique cases or very small series [28]. According to this review, ECT treatment was used for mood disorders in $72 \%$ of cases. A substantial improvement or complete disappearance of symptoms was seen in $53 \%$ of the subjects and in $70 \%$ of the mood disorder cases. We recently conducted a meta-analysis of the nine retrospective studies including ten or more patients that have been published since 1993 [16]. Two of them were controlled trials $[7,25]$. This meta-analysis confirmed the results obtained in Rey and Walter's review [28]. In particular, 9 of 11 patients (82\%) treated with ECT for a catatonic syndrome experienced improvement [16]. However, the first line treatment of catatonia is benzodiazepine, which must be given in high dosages (e.g., up to $20 \mathrm{mg} /$ day of lorazepam) [20]. In our case, sedation limited the use of such a high dosage.

ECT's side effects in young people are rarely studied. No deaths have been reported in adolescents [22]. The theoretical risk is similar to that of brief general anaesthesia. ECT side effects described in adolescents include transient memory impairments, prolonged seizures (more frequent in adolescents than in adults) and tardive seizures, and other benign and transitory effects (headaches, confused states, nausea, muscular pains) [23, 38]. Eleven bipolar adolescents treated for severe mood episodes underwent a cognitive evaluation 4 years later on average and were compared with adolescents matched for age, sex and diagnosis and not treated with ECT. No objective significant difference was found in longterm anterograde memory or in academic delay, even though subjective memory problems were reported by two subjects from the ECT group [15, 32]. Furthermore, two groups studied patients' and parents' experiences and opinions concerning ECT in young people $[33,39]$. In general, the two studies showed that patients and their parents had a positive attitude toward ECT, even though the treatment frightened the adolescents and their parents initially. The current case confirms that ECT is a frightening treatment for young people and that subjective memory impairment is the main issue among the secondary effects. It may be related to poor biographical memory that was not assessed in the patient. Notably, ECT was a complex decision for J's parents, and we cannot exclude the possibility that our ECT schedule was occasionally disrupted by social and parental factors. A therapeutic alliance with the family is crucial for helping them make the decision, as parents may be a source of anxiety.

Treatment of catatonia is mainly symptomatic, and sedative drugs (in particular lorazepam) are the first options [17, 36]. However, chronic presentations prove to be more challenging to treat and have shown poor responses to standard therapeutics in adult studies [35]. ECT is a recommended option in resistant cases [34]. This case supports the view that ECT should not be banned in teens and that it is a therapeutic option in catatonia as well. Similarly, maintenance ECT may be indicated in case of relapse of a condition that responded to an ECT course, including mood disorders and schizophrenia [2, 8, 10]. This case illustrates the importance of maintenance ECT as a treatment option in adolescents with severe psychiatric conditions. More research to assess indications, technicity, effectiveness and safety is warranted.

\section{References}

1. ANAES (1998) Indications et modalités de l'electrconvulsivothérapie.

http://www.anaes.fr
2. Andrade C, Kurinji S (2002) Continuation and maintenance ECT: a review of recent research. J ECT 18:149-158
3. APA (2001) The practice of electroconvulsive therapy: recommendations for treatment, training, and privileging. American Psychiatric Association, www.psych.org 
4. Bailine SH, Petraviciute S (2007) Catatonia in autistic twin: role of electroconvulsive therapy. J ECT 23:21-22

5. Baker T (1995) ECT and young minds. Lancet 345:65

6. Baker T (1995) The minor issue of electroconvulsive therapy. Nat Med 1:199-200

7. Bloch Y, Levcovitch Y, Bloch AM, Mendlovic S, Ratzoni G (2001) Electroconvulsive therapy in adolescents: similarities to and differences from adults. J Am Acad Child Adolesc Psychiatry 40:1332-1336

8. Braga RJ, Petrides G (2005) The combined use of electroconvulsive therapy and antipsychotics in patients with schizophrenia. J ECT 21:75-83

9. Bush G, Fink M, Petrides G, Dowling F, Francis A (1996) Catatonia. I. Rating scale and standardized examination. Acta Psychiatr Scand 93:129-136

10. Chanpatanna W (2000) Maintenance ECT in treatment-resistant schizophrenia. J Med Assoc Thai 83:657-662

11. Cohen D (2006) Towards a valid nosography and psychopathology of catatonia in children and adolescents. Int Rev Neurobiol 72:131-147

12. Cohen D, Flament M, Dubos PF, Basquin M (1999) Case series: catatonic syndrome in young people. J Am Acad Child Adolesc Psychiatry 38:1040-1046

13. Cohen D, Nicolas JD, Flament MF, Perisse D, Dubos PF, Bonnot O, Speranza M, Graindorge C, Tordjman S, Mazet P (2005) Clinical relevance of chronic catatonic schizophrenia in children and adolescents: evidence from a prospective naturalistic study. Schizophr Res 76:301-308

14. Cohen D, Paillere-Martinot ML, Basquin M (1997) Use of electroconvulsive therapy in adolescents. Convuls Ther 13:25-31

15. Cohen D, Taieb O, Flament M, Benoit N, Chevret S, Corcos M, Fossati P, Jeammet P, Allilaire JF, Basquin M (2000) Absence of cognitive impairment at long-term follow-up in adolescents treated with ECT for severe mood disorder. Am J Psychiatry 157:460-462

16. Consoli A, Deniau E, Huynh C, Purper D, Cohen D (2007) Treatments in child and adolescent bipolar disorders. Eur Child Adolesc Psychiatry 16:187-198
17. Cornic F, Consoli A, Cohen D (2007) Catatonia in children and adolescents. Psychiatr Ann 37:19-26

18. Duffett R, Hill P, Lelliott P (1999) Use of electroconvulsive therapy in young people. Br J Psychiatry 175:228-230

19. Fink M, Coffey CE (1998) Electroconvulsive therapy. In: Coffey CE, Brumback R (eds) Texbook of pediatric neuropsychiatry. American Psychiatric Press, Washington, DC

20. Fink M, Taylor MA (2003) Catatonia: a clinican's guide to diagnosis and treatment. Cambridge University Press, Cambridge

21. Ghaziuddin N, King CA, Naylor MW, Ghaziuddin M, Chaudhary N, Giordani B, Dequardo JR, Tandon R, Greden J (1996) Electroconvulsive treatment in adolescents with pharmacotherapyrefractory depression. J Child Adolesc Psychopharmacol 6:259-271

22. Ghaziuddin N, Kutcher SP, Knapp P, Bernet W, Arnold V, Beitchman J, Benson RS, Bukstein O, Kinlan J, McClellan J, Rue D, Shaw JA, Stock S, Kroeger Ptakowski K (2004) Practice parameter for use of electroconvulsive therapy with adolescents. J Am Acad Child Adolesc Psychiatry 43:1521-1539

23. Ghaziuddin N, Laughrin D, Giordani B (2000) Cognitive side effects of electroconvulsive therapy in adolescents. J Child Adolesc Psychopharmacol 10: 269-276

24. Kazooga-Mwesibe A, Watchel L, Dhossche D (2008) Catatonia in autism: implication across lifetime. Eur Child Adolesc Psychiatry 17(6):327-335

25. Kutcher SP, Robertson HA (1995) Electroconvulsive therapy in treatment-resistant bipolar youth. J Child Adolesc Psychopharmacol 5:167-175

26. Lehman AF, Lieberman JA, Dixon LB, McGlashan TH, Miller AL, Perkins DO, Kreyenbuhl J (2004) Practice guideline for the treatment of patients with schizophrenia, second edition. Am J Psychiatry 161:1-56

27. Moise FN, Petrides G (1996) Case study: electroconvulsive therapy in adolescents. J Am Acad Child Adolesc Psychiatry 35:312-318

28. Rey JM, Walter G (1997) Half a century of ECT use in young people. Am J Psychiatry 154:595-602
29. Schneekloth MD, Rummans T, Logan KM (1993) Electroconvulsive therapy in adolescents. Convuls Ther 9:158-166

30. Squire LR, Wetzel CD, Slater PC (1979) Memory complaint after electroconvulsive therapy: assessment with a new self-rating instrument. Biol Psychiatry 14:791-801

31. Strober M, Rao U, DeAntonio M, Liston E, State M, Amaya-Jackson L, Latz S (1998) Effects of electroconvulsive therapy in adolescents with severe endogenous depression resistant to pharmacotherapy. Biol Psychiatry 43:335-338

32. Taieb O, Flament MF, Chevret $S$, Jeammet P, Allilaire JF, Mazet P, Cohen D (2002) Clinical relevance of electroconvulsive therapy (ECT) in adolescents with severe mood disorder: evidence from a follow-up study. Eur Psychiatry 17:206-212

33. Taieb O, Flament MF, Corcos M, Jeammet $\mathrm{P}$, Basquin $\mathrm{M}$, Mazet $\mathrm{P}$, Cohen D (2001) Electroconvulsive therapy in adolescents with mood disorder: patients' and parents' attitudes. Psychiatry Res 104:183-190

34. Taylor MA, Fink M (2003) Catatonia in psychiatric classification: a home of its own. Am J Psychiatry 160:1233-1241

35. Ungvari GS, Chiu HF, Chow LY, Lau BS, Tang WK (1999) Lorazepam for chronic catatonia: a randomized, double-blind, placebo-controlled crossover study. Psychopharmacology (Berl) 142:393-398

36. Ungvari GS, Leung CM, Wong MK, Lau J (1994) Benzodiazepines in the treatment of catatonic syndrome. Acta Psychiatr Scand 89:285-288

37. Wachtel L, Kahng SW, Dhossche D, Cascella N, Reti IM (2008) ECT for catatonia in an autistic girl. Am J Psychiatry $165: 329-333$

38. Walter G, Rey JM (1997) An epidemiological study of the use of ECT in adolescents. J Am Acad Child Adolesc Psychiatry 36:809-815

39. Walter G, Rey JM, Mitchell PB (1999) Practitioner review: electroconvulsive therapy in adolescents. J Child Psychol Psychiatry 40:325-334 